\title{
Effect of electroosmotic flow of aqueous suspension of nanosilica on the properties of carbonated concrete
}

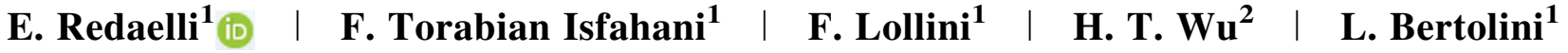

${ }^{1}$ Department of Chemistry, Materials and Chemical Engineering "G. Natta", Politecnico di Milano, via Mancinelli 7, 20131 Milan, Italy

${ }^{2}$ Institute of Structural Engineering, Zhejiang University, Yuhangtang Road 866, Hangzhou, P. R. China

Correspondence

E. Redaelli, Department of Chemistry, Materials and Chemical Engineering "G. Natta", Politecnico di Milano, via Mancinelli 7, 20131 Milan, Italy. Email: elena.redaelli@polimi.it

Funding information

European Research Council, Grant number: FP7PEOPLE-2011-IRSES-294555
The paper investigates the possibility to use electroosmosis to transport nanosilica (NS) particles inside carbonated concrete, in order to exert a filler effect and enhance its durability performance. This method aims to extending possible beneficial effects of NS to existing reinforced concrete structures, where the presence of a carbonated layer of concrete is very likely. Injection tests were performed with electrochemical cells on carbonated concrete discs with water/ cement (w/c) ratios of $0.50,0.55$ and 0.65 , using a NS aqueous suspension at the anode. The results indicated that a flow did occur through the concrete disc and it was directed from the anode towards the cathode. A linear relationship between flux and applied voltage gradient was obtained, which is typical of electroosmotic phenomena. The bulk properties of concrete, such as density, water absorption and sorptivity, were not affected by the injection tests, whilst electrical resistivity increased indicating a mild 'sealing' effect on the surface. Also microstructural analyses highlighted the local presence of NS that decreased the local porosity close to the surface.

\section{K E Y W O R D S}

carbonated concrete, electroosmosis, injection, nanosilica

\section{1 | INTRODUCTION}

The application of an electrical current to hardened concrete produces several transport phenomena that affect its properties as well as the corrosion behaviour of embedded reinforcement. These phenomena have been exploited with the aim of improving concrete performance, e.g. to remove chlorides or other contaminants from concrete, ${ }^{[1,2]}$ to inject inhibitors that protect reinforcement from corrosion ${ }^{[3]}$ and to restore concrete alkalinity. ${ }^{[4]}$ Some of these methods have been used for decades and are effective in improving concrete resistance to aggressive environments and enhancing its durability ${ }^{[5]}$ More recently, the application of a current has been proposed to induce the transport of charged nanoparticles of silica inside concrete with the aim of reducing its porosity through a combined 'filler' effect and chemical reaction with hydrated cement paste related with pozzolanic activity ${ }^{[6-9]}$ This application would be very powerful since it would allow extending the potential benefits related with the use of nanosilica (NS) in concrete - usually admixed to the ingredients $^{[10,11]}$ - to existing structures that are suffering deterioration phenomena. However, although most references claim very promising results in alkaline concrete, this methodology is still in the laboratory stage and needs further investigation.

The characterisation of transport in concrete under an electric field is a rather complex topic that involves several phenomena including the properties of the solid material, the composition of the liquid and the interaction between solid and liquid. ${ }^{[12]}$ For instance, it is well known that when a voltage gradient is applied across a cementitious material in saturated condition, an electroosmotic flow of water occurs; however, this flow is affected by many parameters and in the scientific literature there is no agreement on the entity of the flow and its direction. ${ }^{[13-15]}$ In fact, while some authors reported a flow mainly directed from the anode towards the 
cathode (as it occurs for soils and most construction materials like fired clay bricks), ${ }^{[13,15]}$ other authors reported an inversion of the direction of the flow for alkaline mortar (from cathode to anode) with respect to carbonated mortar (from anode to cathode). ${ }^{[14]}$ The presence of particles of NS in the liquid phase may further affect the resulting transport since, although NS is overall neutral, it may be characterised by the presence of a surface charge that will affect its behaviour under an electric field. NS in water is characterised by a negative surface charge; because of this some authors proposed to modify its surface by adding nanoalumina particles that make the surface charge positive, so that NS can be transported inside concrete. ${ }^{[6]}$

This paper presents the results of an experimental research aimed at investigating the effects of electroosmosis applied to carbonated concrete using a NS suspension at the anode, instead of water. This approach relies on the results of a previous research that showed that in carbonated mortar, the electroosmotic flow of water occurs in the direction from the anode towards the cathode, whilst in non-carbonated mortar, the flow of water occurs in opposite direction, i.e. from the cathode towards the anode. Hence, the electroosmotic flow could be exploited to drag non-charged particles of nanosilica inside carbonated concrete, in order to promote a filler effect of these particles inside the pores, and rely on the beneficial consequences of a reduced porosity, with particular regard to the durability properties of concrete. It should be noted that, contrary to freshly made laboratory specimens, that are usually fully alkaline, the presence of a carbonated layer of concrete is very likely in real conditions. Hence, because the carbonation of cementitious materials affects the electroosmotic transport, this may in turn affect the applicability and effectiveness on existing structures. So far, this aspect has not received much attention in the scientific literature.

To this purpose, carbonated concrete discs were subjected to electroosmotic tests using a NS suspension at the anode and the effects on concrete were evaluated by comparing its properties before and after the treatment, with specific reference to durability properties.

\section{2 | MATERIALS AND METHODS}

The experimental activity consisted in the application of a current across concrete discs mounted in an electrochemical cell with one surface in contact with a nanosilica suspension and the other surface in contact with water. This test will be referred to as injection test. The effect of the injection test was evaluated by comparing some properties of concrete before and after the treatment.

Three concrete mixtures were considered, with water/ cement ratios of $0.50,0.55$ and 0.65. CEM I 42.5R cement, crushed limestone aggregate with maximum size of $12.5 \mathrm{~mm}$,
TABLE 1 Composition of concrete mixtures and properties at fresh and hardened state $\left(R_{c, 7 d}\right.$ and $R_{c, 28 d}$ are average compressive strengths of two cubic specimens after 7 and 28 days of wet curing, respectively)

\begin{tabular}{llll} 
w/c & $\mathbf{0 . 5 0}$ & $\mathbf{0 . 5 5}$ & $\mathbf{0 . 6 5}$ \\
\hline CEM I 42.5R $\left(\mathrm{kg} \mathrm{m}^{-3}\right)$ & 366 & 344 & 308 \\
Water $\left(\mathrm{kg} \mathrm{m}^{-3}\right)$ & 183 & 189 & 200 \\
\hline Aggregate $\left(\mathrm{kg} \mathrm{m}^{-3}\right)$ & 1845 & 1848 & 1849 \\
Superplasticiser $\left(\mathrm{kg} \mathrm{m}^{-3}\right)$ & 1.8 & 2.4 & 1.5 \\
\hline Fresh state & & & \\
Slump $(\mathrm{mm})$ & 50 & 240 & 175 \\
\hline Hardened state & & & \\
$\mathrm{R}_{\mathrm{c}, 7 \mathrm{~d}}(\mathrm{MPa})$ & 47.8 & 41.4 & 30.4 \\
$\mathrm{R}_{\mathrm{c}, 28 \mathrm{~d}}(\mathrm{MPa})$ & 57.2 & 49.2 & 33.9 \\
\hline
\end{tabular}

demineralised water and an acrylic-type superplasticiser were used. Concrete compositions are reported in Table 1, together with early properties of concrete at fresh and hardened state.

Slabs with size of $250 \times 395 \times 60 \mathrm{~mm}^{3}$ were cast and, after 28 days of wet curing, cylindrical specimens with nominal diameter of $100 \mathrm{~mm}$ were cored. After grinding off the top and bottom layers, the cylinders were sliced into discs with thickness of $10 \mathrm{~mm}$, which were subjected to accelerated carbonation in a chamber with $4 \% \mathrm{CO}_{2}$. Carbonation was verified on sacrificial specimens.

After complete carbonation, the discs were saturated with demineralised water and subjected to electroosmotic tests. Each disc separated the two compartments of an electrochemical cell; the volume of each compartment was about $600 \mathrm{ml}$. The cathodic and anodic compartments were filled with water and nano-silica (NS) suspension, respectively. NS suspension was a commercial product from Tec Star and it was produced by dispersing NS particles with average size of $20 \mathrm{~nm}$ in water with a concentration of $10 \%$ by mass. Activated titanium meshes were used as electrodes in each compartment and were connected to a DC current generator. Each compartment included a graduated vertical tube that allowed to detect the flow of liquid through the disc by measuring the variation of the liquid level.

The injection tests consisted in the application of nominal direct current densities of 0.5 and $2 \mathrm{~A} \mathrm{~m}^{-2}$ (referred to the net surface of the disc in contact with the liquid) for $24 \mathrm{~h}$; the corresponding circulated charge densities were 12 and $48 \mathrm{~A} \mathrm{~h} \mathrm{~m}^{-2}$, respectively. Specifically, the tests at $0.5 \mathrm{~A} \mathrm{~m}^{-2}$ were carried out with partial durations of $8 \mathrm{~h}$ per day for 3 days. The tests with $2 \mathrm{~A} \mathrm{~m}^{-2}$ had a longer duration, to account for the lower circulating current with respect to the nominal value (the generator reached the maximum feeding voltage of about $23 \mathrm{~V}$, so the nominal current could not be supplied). In the latter case, the duration was increased to $40 \mathrm{~h}$ (8 h per day for 5 days).

During the injection test, approximately every $2 \mathrm{~h}$, the circulating current and feeding voltage (on and instant-off values) were measured, together with the level of the solution 
in the vertical tubes (after removing bubbles); the level was brought back to the initial zero level.

Both before and after the injection treatment the discs were characterised with measurements of mass/density, sorptivity, water absorption and electrical resistivity. Similar characterisation tests were carried out on reference noncarbonated concrete specimens, and results are reported elsewhere. ${ }^{[11]}$

Sorptivity test was performed after drying the disc at $40{ }^{\circ} \mathrm{C}$ for a week, then the injected face (i.e. the one in contact with the NS suspension in the anode compartment) was laid on water and the mass of the disc was measured at $12 \mathrm{~min}$, $30 \mathrm{~min}, 1 \mathrm{~h}, 2 \mathrm{~h}, 4 \mathrm{~h}$ and $24 \mathrm{~h}$. The sorptivity coefficient $\mathrm{S}$ (in $\mathrm{kg} \mathrm{m}^{-2} \mathrm{~h}^{-0.5}$ ) was evaluated by linear interpolation of the mass per unit surface versus square root of time (with the least squares method). After the sorptivity test, the discs were completely immersed in water for $48 \mathrm{~h}$, and the water absorption $W$ (in \%) was evaluated as

$$
W=\frac{m_{\mathrm{SAT}}-m_{\mathrm{DRY}}}{m_{\mathrm{DRY}}} \cdot 100
$$

where $m_{\mathrm{SAT}}$ and $m_{\mathrm{DRY}}$ (in $\mathrm{g}$ ) are the masses of saturated and dry disc, respectively.

Electrical resistivity $\rho$ (in $\Omega \mathrm{m}$ ) was obtained as

$$
\rho=\frac{A}{C \cdot H}
$$

where $C$ (in $\mathrm{S}$ ) is the conductance across the saturated disc, and $A$ (in $\mathrm{m}^{2}$ ) and $H$ (in $\mathrm{m}$ ) are the surface and thickness of the disc, respectively.

Microstructural characterisation tests were performed by means of mercury intrusion porosimetry (MIP) on fragments taken from selected discs. Finally, fragments taken from all discs were observed with ESEM.

\section{3 | RESULTS}

\subsection{Measurements on the cells}

Figures 1-3 summarise the evolution of the level of the liquid in the cathodic and anodic compartments during the electroosmotic injection treatment. In general, the level increased at the cathode and decreased at the anode; variations were symmetric with respect to the time axis and they were linear in time, indicating a constant flow of liquid across the disc, with direction from the anode towards the cathode. At a given time, the variations increased with the nominal applied current: for instance, passing from 0.5 to $2 \mathrm{~A} \mathrm{~m}^{-2}$, the level of the liquid in the cathode compartment at $24 \mathrm{~h}$ passed from 32 to $46 \mathrm{~mm}$ for $\mathrm{w} / \mathrm{c}=0.5$ (Figure 1), from 47 to $110 \mathrm{~mm}$ for $\mathrm{w} / \mathrm{c}=0.55$ (Figure 2) and from 61 to $89 \mathrm{~mm}$ for $\mathrm{w} / \mathrm{c}=0.65$ (Figure 3).
Figures 4 and 5 show the evolution of current density and feeding voltage, respectively. In the tests with nominal applied current of $0.5 \mathrm{~A} \mathrm{~m}^{-2}$ the feeding voltage showed a decreasing trend with time, and at the end of the test it reached values of about $7 \mathrm{~V}$ for $\mathrm{w} / \mathrm{c}=0.65$ and $13-14 \mathrm{~V}$ for $\mathrm{w} / \mathrm{c}=0.55$ and 0.5 . In the tests with nominal applied current of $2 \mathrm{~A} \mathrm{~m}^{-2}$, the generator reached the maximum feeding voltage of about $23 \mathrm{~V}$, and the nominal current could not be supplied. Hence, the real current density assumed lower values of about $0.7 \mathrm{~A} \mathrm{~m}^{-2}$ for $\mathrm{w} / \mathrm{c}=0.50,0.9 \mathrm{~A} \mathrm{~m}^{-2}$ for $\mathrm{w} / \mathrm{c}=0.55$ and $1.2 \mathrm{~A} \mathrm{~m}^{-2}$ for $\mathrm{w} / \mathrm{c}=0.65$. In consequence of this, the duration of the test at $2 \mathrm{~A} \mathrm{~m}^{-2}$ was increased to $40 \mathrm{~h}$, as already mentioned.

At the end of all tests, the solution in the cathode compartment remained clear and the NS suspension in the anode compartment remained opaque. In addition, in the anode compartment agglomeration of the suspension occurred both at the electrode surface and at the specimen surface, as indicated by the formation of a dense gel. An example of the appearance of the injected concrete surface is shown in Figure 6. The gel was removed by washing under tap water.

\section{2 | Characterisation of concrete}

Figure 7 shows the density of concrete discs before and after the injection test. The initial density that was measured on the discs before the injection was around $2.45-2.69 \mathrm{~g} \mathrm{~cm}^{-3}$, i.e. slightly higher compared to the values that were measured on non-carbonated cubes after 28 days of wet curing, ${ }^{[11]}$ that were around $2.34 \mathrm{~g} \mathrm{~cm}^{-3}$ for $\mathrm{w} / \mathrm{c}=0.65,2.45 \mathrm{~g} \mathrm{~cm}^{-3}$ for $\mathrm{w} / \mathrm{c}=0.55$ and $2.47 \mathrm{~g} \mathrm{~cm}^{-3}$ for $\mathrm{w} / \mathrm{c}=0.50$. This difference is likely due to the carbonation phenomenon and to the condition of saturation, to which the discs were subjected before the injection test. Moreover, the relatively small size of the discs made them more susceptible to local heterogeneities of concrete (e.g. relative amount of aggregate and cement paste). Yet, the density of each single disc remained virtually the same after the injection test.

Figure 8 shows an example of the evolution of the electrical resistivity of the discs. The discs were kept in watersaturated conditions, so as to minimise the changes in the electrical resistivity related with changes in humidity content. Before the treatment, the resistivity of the carbonated discs was around $930-950 \Omega \mathrm{m}$ for $\mathrm{w} / \mathrm{c}=0.65$ and 0.55 and $1280 \Omega \mathrm{m}$ for $\mathrm{w} / \mathrm{c}=0.50$. Comparing the average values of electrical resistivity of each single disc before and after the injection test (Figure 9), a slight increase was observed, with the exception of the disc with $\mathrm{w} / \mathrm{c}=0.65$ subjected to $0.5 \mathrm{~A} \mathrm{~m}^{-2}$, that retained its initial value.

Figures 10 and 11 compare the sorptivity and water absorption, respectively. The initial values showed a substantial scatter that, again, can be attributed to heterogeneities of concrete discs, and they were between 0.23 and 

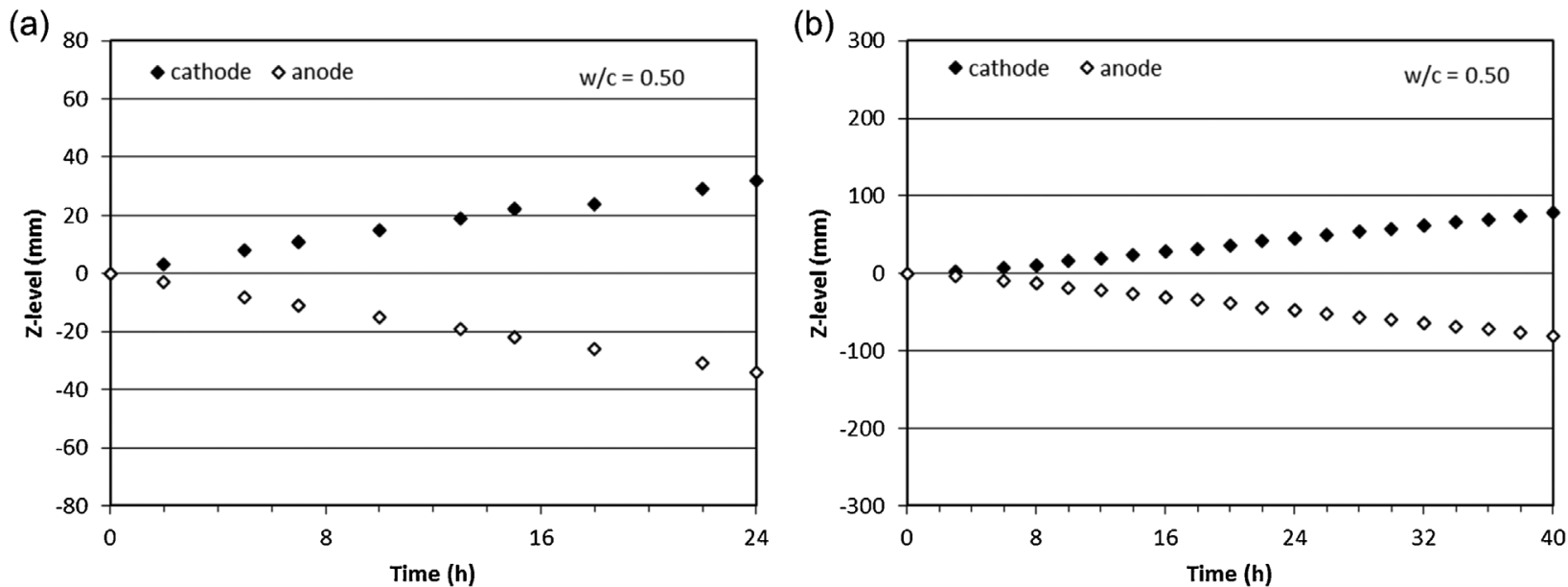

FIGURE 1 Level of the liquid in the cathodic and anodic compartments during the electroosmotic injection treatment on carbonated concrete with w/c $=0.50$ with nominal applied current of $0.5 \mathrm{~A} \mathrm{~m}^{-2}$ (a) and $2 \mathrm{~A} \mathrm{~m}^{-2}$ (b)

(a)

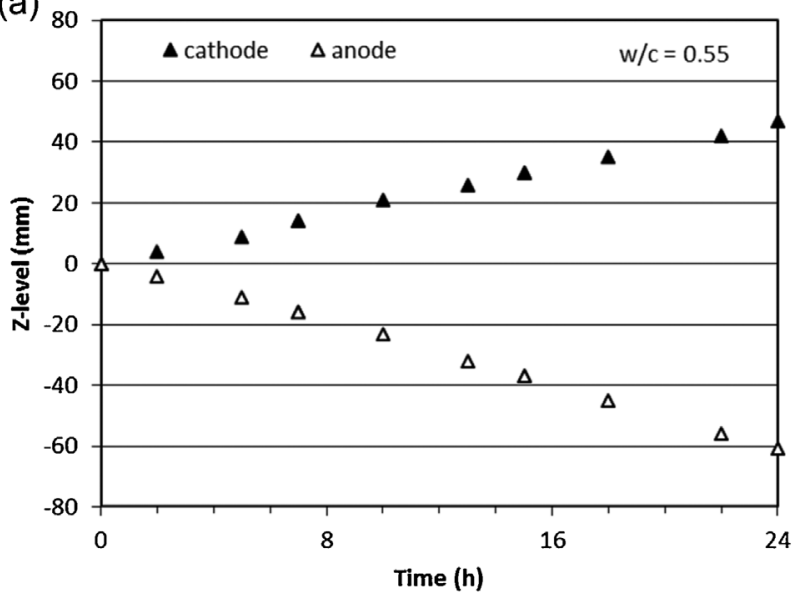

(b)

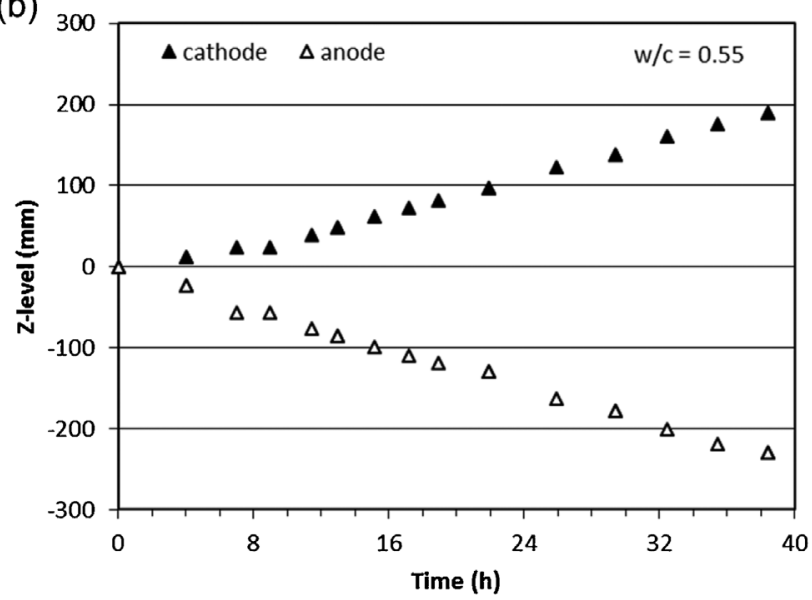

FIGURE 2 Level of the liquid in the cathodic and anodic compartments during the electroosmotic injection treatment on carbonated concrete with w/c $=0.55$ with nominal applied current of $0.5 \mathrm{~A} \mathrm{~m}^{-2}$ (a) and $2 \mathrm{~A} \mathrm{~m}^{-2}$ (b)
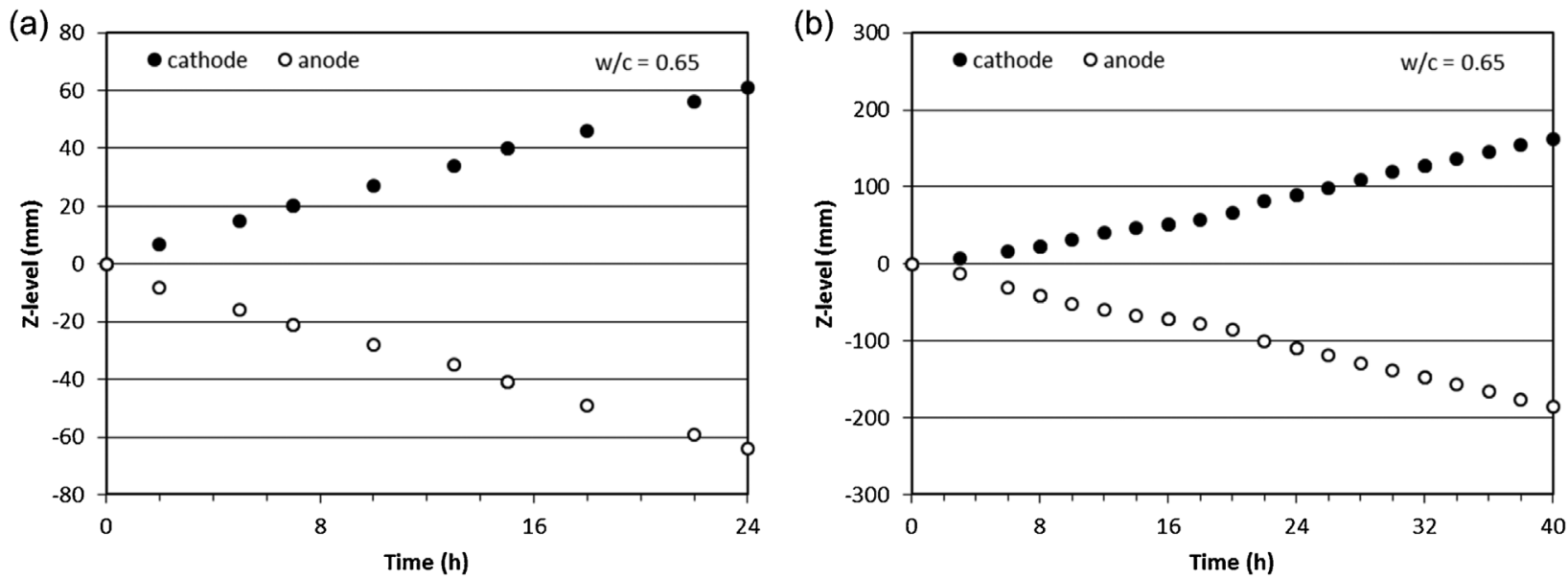

FIGURE 3 Level of the liquid in the cathodic and anodic compartments during the electroosmotic injection treatment on carbonated concrete with w/c $=0.65$ with nominal applied current of $0.5 \mathrm{~A} \mathrm{~m}^{-2}$ (a) and $2 \mathrm{~A} \mathrm{~m}^{-2}$ (b) 

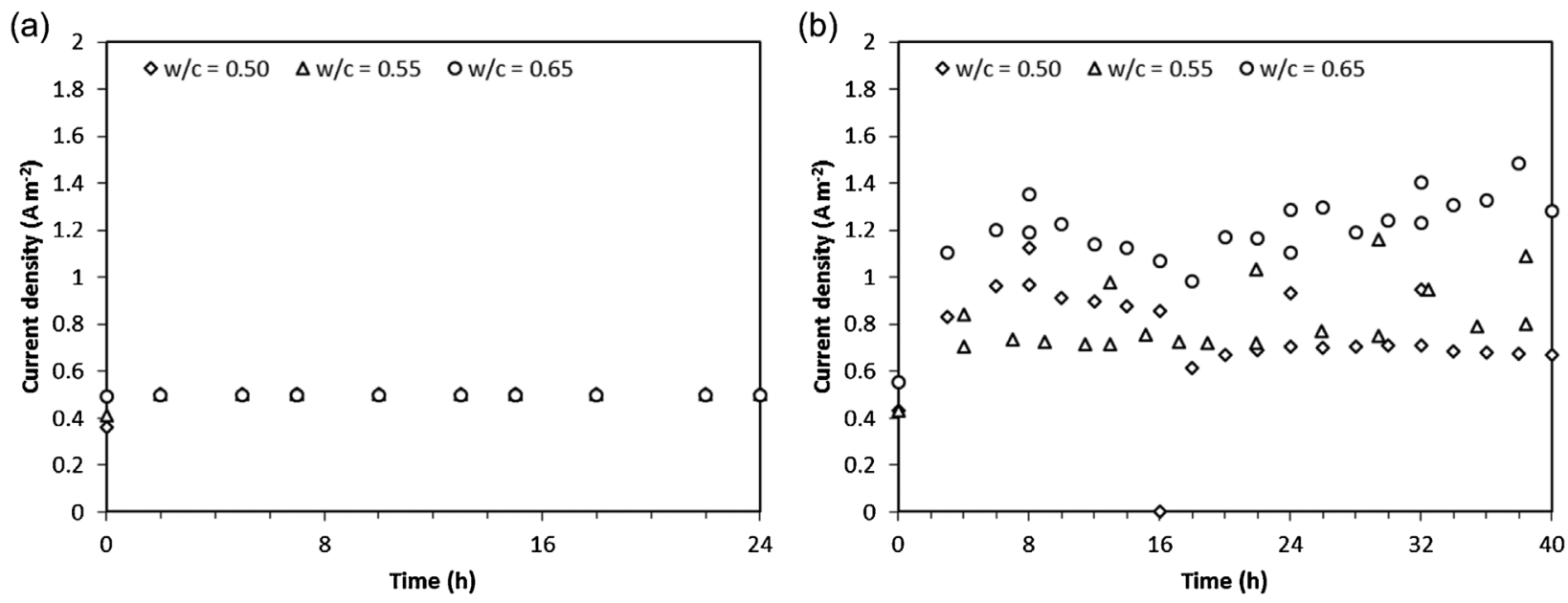

FIGURE 4 Current density during the electroosmotic injection treatment with nominal applied current of $0.5 \mathrm{~A} \mathrm{~m}^{-2}$ (a) and $2 \mathrm{~A} \mathrm{~m}^{-2}$ (b)

$0.55 \mathrm{~kg} \mathrm{~m}^{-2} \mathrm{~h}^{-0.5}$ for sorptivity and between 3.35 and $5.07 \%$ for water absorption. As a comparison, values measured on non-carbonated cylinders were of the order of 0.65 $0.68 \mathrm{~kg} \mathrm{~m}^{-2} \mathrm{~h}^{-0.5}$ and $5.4-5.8 \% .^{[11]}$ For both parameters, no substantial changes occurred after the injection tests.

Figure 12 shows the cumulative intrusion curves obtained from MIP tests on fragments taken from the discs; for comparison, also data of non-carbonated concrete are reported ${ }^{[11]}$ For $w / c=0.65$, specimens subjected to injection tests both at 0.5 and $2 \mathrm{~A} \mathrm{~m}^{-2}$ showed a reduction in the total cumulative volume of pores as well as the pore size; this reduction was more pronounced for $0.5 \mathrm{~A} \mathrm{~m}^{-2}$. A similar reduction was observed on the specimen with $\mathrm{w} / \mathrm{c}=0.50$ treated with $0.5 \mathrm{~A} \mathrm{~m}^{-2}$, whilst the specimen treated with $2 \mathrm{~A} \mathrm{~m}^{-2}$ showed an increase in the total cumulative volume with respect to the untreated carbonated concrete. Table 2 summarises the results in terms of total cumulative volume of pores.

Finally, Figure 13 shows some examples of the images obtained with ESEM, that were aimed at highlighting possible presence of particles or clusters of NS, both through microstructure observation and chemical analysis with EDS. Being concrete fully carbonated, NS particles were not expected to give rise to pozzolanic reaction, but rather to retain their nature and shape. However, being characterised by a similar nature as cement paste, they were hard to distinguish chemically. A massive presence of NS was not detected; only occasionally NS could be observed. A systematic reduction of concrete porosity in the vicinity of the anodic surface could not be detected, either.

\section{4 | DISCUSSION}

The results obtained from the various tests will be discussed in relation with the possibility of injecting NS particles into carbonated concrete by means of an electroosmotic mechanism, i.e. dragging them through a water flow, and the subsequent effects on concrete with specific reference to durability properties. The injection test that was performed in

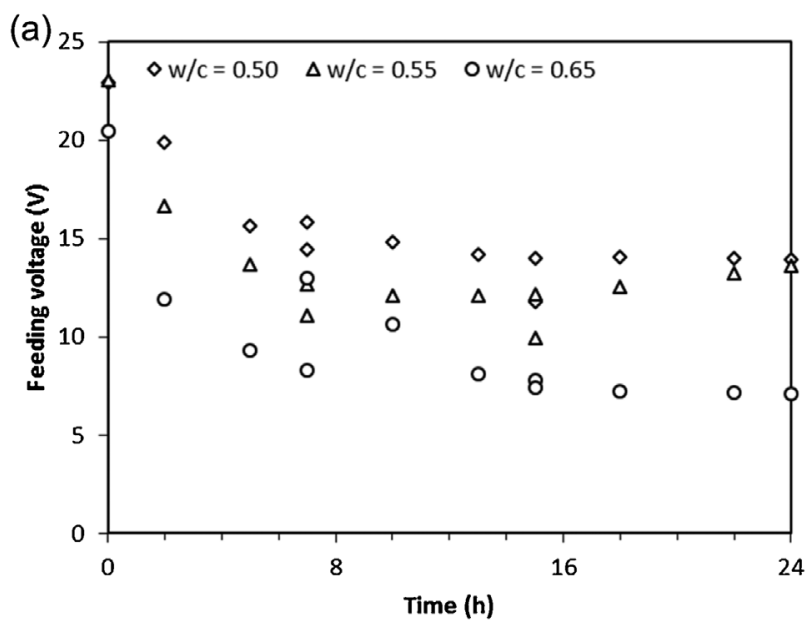

(b)

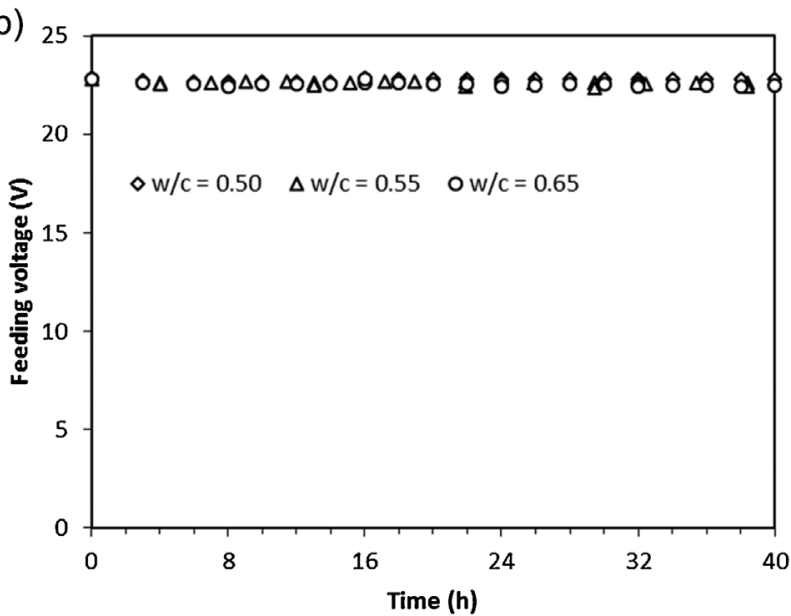

FIGURE 5 Feeding voltage during the electroosmotic injection treatment with nominal applied current of $0.5 \mathrm{~A} \mathrm{~m}^{-2}$ (a) and $2 \mathrm{~A} \mathrm{~m}^{-2}$ (b) 


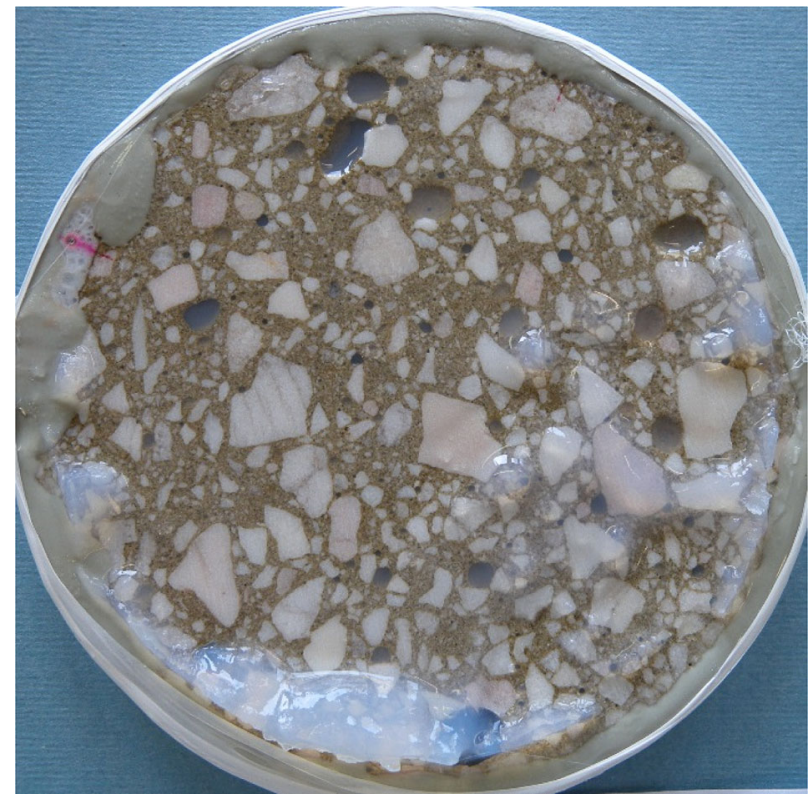

FIGURE 6 Appearance of the injected surface of a specimen with w/c of 0.65 after the injection test at $2 \mathrm{~A} \mathrm{~m}^{-2}$ for $40 \mathrm{~h}$. [Color figure can be viewed at wileyonlinelibrary.com]

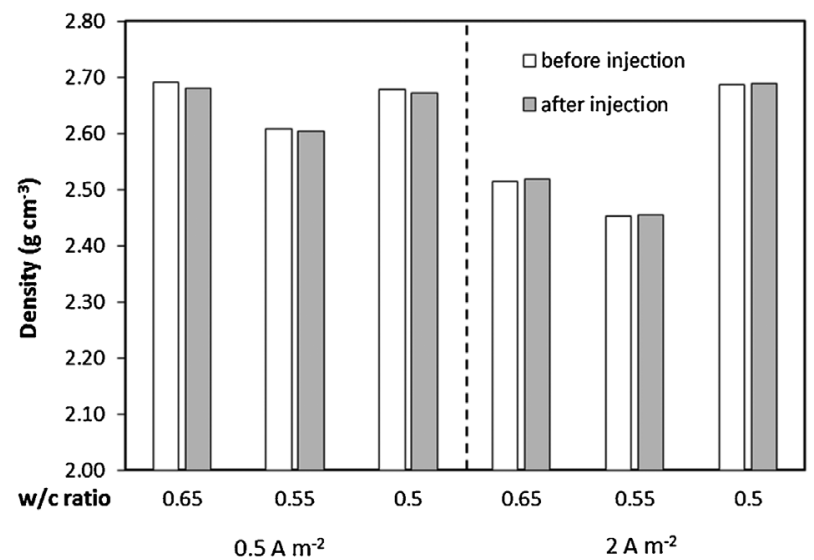

FIGURE 7 Density of concrete discs before and after injection test

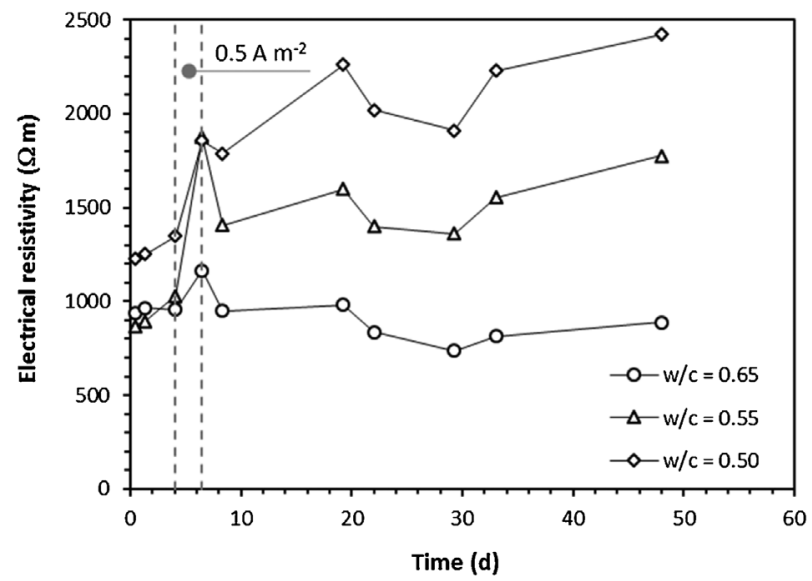

FIGURE 8 Evolution of electrical resistivity of water-saturated concrete discs subjected to NS injection at $0.5 \mathrm{~A} \mathrm{~m}^{-2}$. Dotted lines indicate duration of injection test

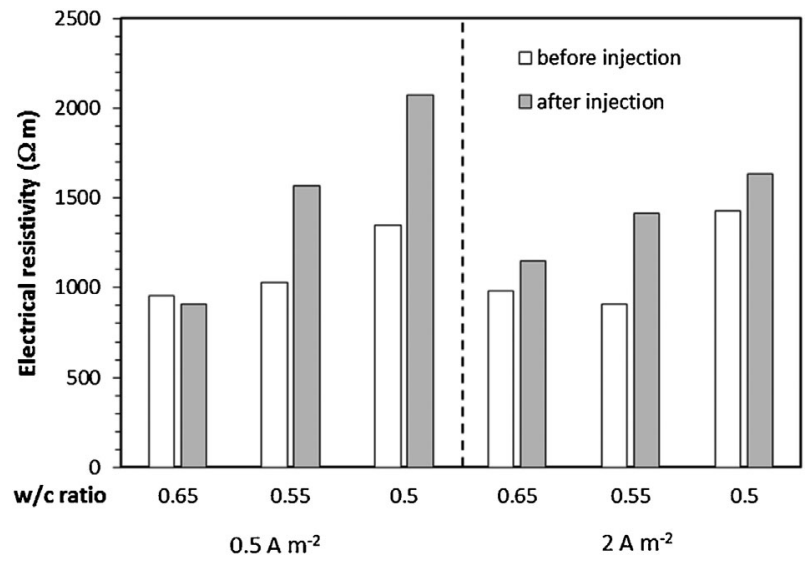

FIGURE 9 Electrical resistivity of water-saturated concrete discs before and after injection test

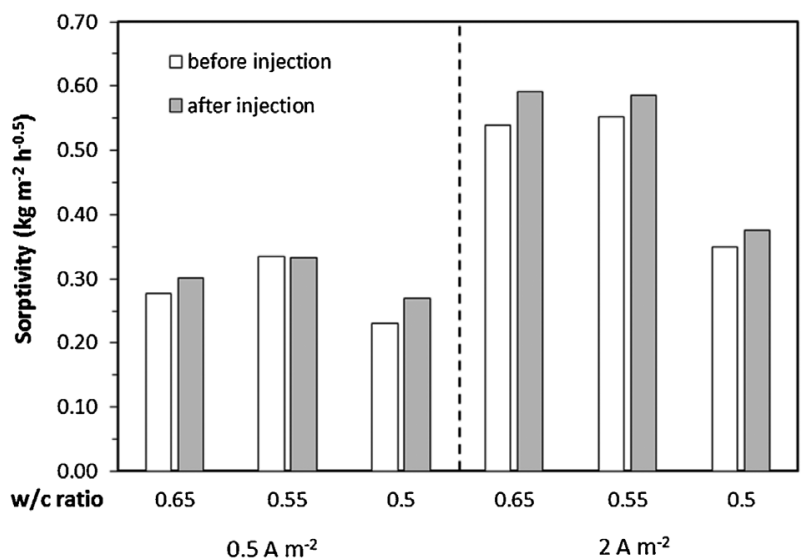

FIGURE 10 Sorptivity of concrete discs before and after injection test

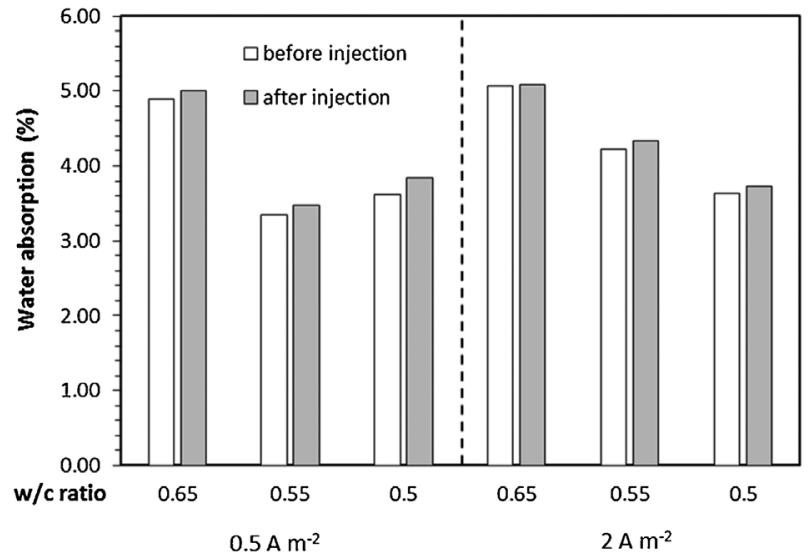

FIGURE 11 Water absorption of concrete discs before and after injection test 

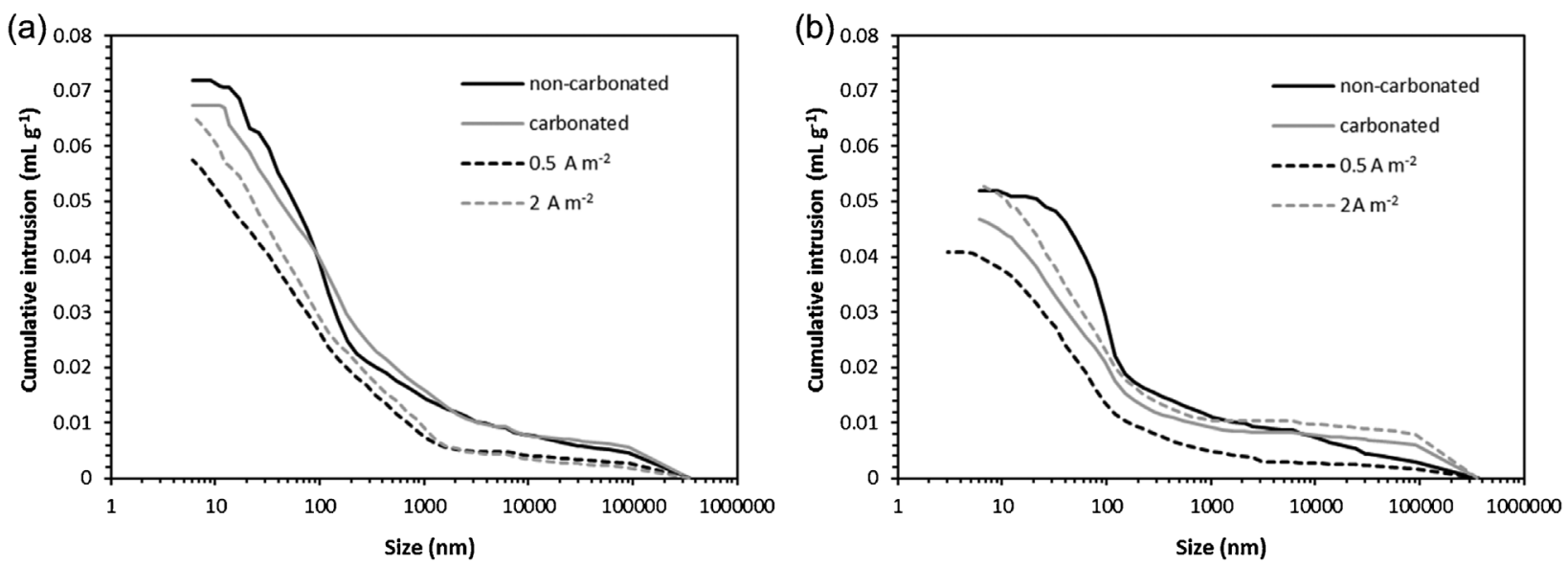

FIGURE 12 Cumulative intrusion curve of concretes with w/c $=0.65$ (a) and w/c $=0.50$ (b)

this research is representative of a situation in which, in a real reinforced concrete structure, the current is applied to the reinforcement (as it is shown in the graphical abstract).

In all injection tests, the variation of the level of the liquid in the anodic and cathodic compartments highlighted that a flow did occur through the concrete disc and it was directed from the anode towards the cathode. As it is shown in Figure 14, a linear relationship between flux and applied voltage gradient was obtained, which is typical of electroosmotic phenomena. ${ }^{[12]}$ This flow can be compared with that previously observed when plain electroosmosis was applied to carbonated mortar, using water at both anode and cathode compartments of the cell. ${ }^{[14]}$ In the presence of NS, higher voltages were required compared to plain electroosmosis in carbonated mortar: in the presence of NS a voltage gradient of $1000-1500 \mathrm{~V} \mathrm{~m}^{-1}$ was necessary to produce a flux of $0.02 \mathrm{ml} \mathrm{m}^{-2} \mathrm{~s}^{-1}$, whilst the same flux was produced by a voltage gradient of $250 \mathrm{~V} \mathrm{~m}^{-1}$ when plain electroosmosis was applied. This difference can be attributed partly to the higher imperviousness of concrete compared to mortar (the water absorption of mortar was twice that of concrete) and partly to a reduced effectiveness of electroosmosis in the presence of NS in the anode compartment. The voltage gradients were overall very high and, from a practical point of view, increasing the electroosmotic flux through an increase of the applied current would not be possible for safety reasons. Anyway, the results highlighted that an electroosmotic flux occurred even in the presence of a NS suspension instead of water in the anode compartment. Hence, the proposed mechanism of penetration of NS in concrete is possible.

TABLE 2 Total cumulative volume of pores $\left(\mathrm{ml} \mathrm{g}^{-1}\right)$ obtained from MIP

\begin{tabular}{lll} 
w/c & $\mathbf{0 . 5 0}$ & $\mathbf{0 . 6 5}$ \\
\hline Non-carbonated & 0.052 & 0.072 \\
Carbonated & 0.047 & 0.067 \\
\hline After injection at $0.5 \mathrm{~A} \mathrm{~m}^{-2}$ & 0.041 & 0.057 \\
\hline After injection at $2 \mathrm{~A} \mathrm{~m}^{-2}$ & 0.053 & 0.065 \\
\hline
\end{tabular}

At the end of all the injection tests, the solution in the cathodic compartment kept its transparency, indicating that the NS suspension could not go through the entire thickness of the concrete disc. At the same time, the anodic solution increased its concentration, as highlighted by its densification. Since no other mechanisms of water depletion could occur at the anode (the amount of water consumed by evaporation and electrode reaction was negligible), this densification may indicate that the transported liquid was mainly water.

Hence, demonstration of NS injection into concrete was not possible on the sole basis of measurements carried out during injection tests and other tests were performed to investigate the effective transport of NS particles, by comparing some macroscopic properties of concrete before and after the injection treatment. This approach relies on the assumption that, if NS particles penetrated into concrete porosity, they should exert a filler effect that would affect the properties of concrete. Conversely, no chemical reaction between NS and cement paste was expected, since being the concrete fully carbonated, no portlandite was available to give rise to a pozzolanic reaction.

Concrete density is expected to increase after penetration of solid particles of NS inside the pores. The total volume of liquid that flew in the concrete disc was $7-9 \mathrm{ml}$ at $0.5 \mathrm{~A} \mathrm{~m}^{-2}$ and $16-50 \mathrm{ml}$ at $2 \mathrm{~A} \mathrm{~m}^{-2}$. Considering that the initial concentration of the suspension was $10 \%$, and assuming that the suspension as a whole was transported, this would indicate an increase of mass of one gram to few grams. Yet, for all concretes and applied currents, the density did not change after the treatment, indicating that if there was a penetration of NS in concrete, this was either not detectable in terms of mass or compensated by possible opposing phenomena (e.g. dissolution or leaching of constituents of the cement paste), that make the mass of concrete decrease. Nevertheless, it could be hypothesised that the possible penetration of NS was mainly localised at the surface, and so could not affect the bulk properties of concrete. 
(a)

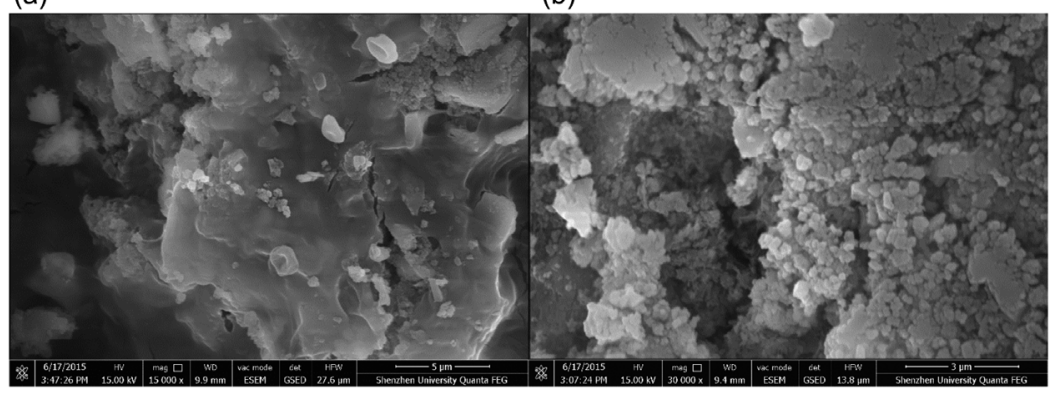

FIGURE 13 Examples of ESEM observations on fragments taken from specimens with w/c $=0.65$ after NS injection at $0.5 \mathrm{~A} \mathrm{~m}^{-2}$ (a) and $2 \mathrm{~A} \mathrm{~m}^{-2}$ (b)

This possibility was further investigated with the measurements of electrical resistivity, sorptivity and water absorption of concrete. Whilst sorptivity and water absorption remained virtually the same, thus confirming density results, resistivity showed an increase after the injection treatment, clearly indicating that the injection treatment produced some effect on concrete. As a matter of fact, in conditions of water saturation, concrete resistivity depends on the microstructure of the pores and on the composition of the pore solution. In particular, a filler effect of NS in the pores, although localised on the concrete surface, may be the reason of the observed increase. This may indicate a mild "sealing" effect of the surface, and it is consistent with the ESEM observation.

This sealing effect was also highlighted by porosity measurements, that showed a considerable reduction of porosity for the injection test at $0.5 \mathrm{~A} \mathrm{~m}^{-2}$ and both $\mathrm{w} / \mathrm{c}$ ratios (Table 2). Compared to resistivity, the MIP tests were performed on small fragments and so should be considered representative of a local portion of the specimen. For the w/c ratio of 0.65 the injection test reduced the porosity from 0.067 to $0.057 \mathrm{ml} \mathrm{g}^{-1}$; the latter value is close to the porosity of the untreated carbonated concrete $\left(0.047 \mathrm{ml} \mathrm{g}^{-1}\right)$. Conversely, the porosity after the treatment at $2 \mathrm{~A} \mathrm{~m}^{-2}$ was either the same $(\mathrm{w} / \mathrm{c}=0.65)$ or even higher $(\mathrm{w} / \mathrm{c}=0.50)$ compared to the reference carbonated concrete. This may be attributed to possible opposing effect of the applied current, as leaching of

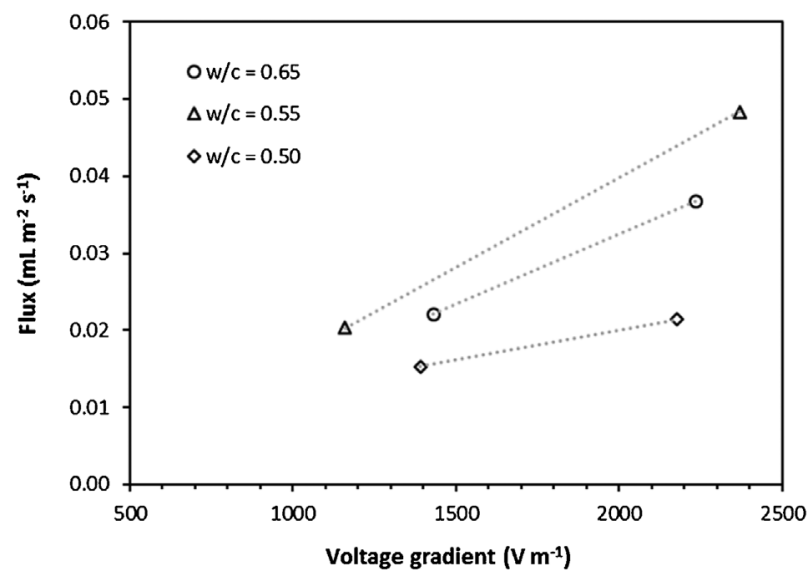

FIGURE 14 Flux of liquid across the concrete specimen as a function of the applied voltage gradient the cement paste produced by the acidic anodic environment. This indicates that, other than already mentioned safety threshold related with the applied voltage, the increase of the applied current or duration of the injection treatment should not be considered as a possible means to enhance the beneficial effects related with NS transport.

\section{5 | CONCLUSIONS}

Carbonated concrete discs were subjected to electroosmotic tests using a NS suspension at the anode as an attempt to inject NS inside concrete and improve its durability properties.

An electroosmotic flow was observed with direction from the anode towards the cathode. The injected liquid was mainly the aqueous phase of the suspension, and only a limited amount of NS was transported into concrete pores.

Bulk properties of concrete, like density and water absorption, were virtually unaffected by the treatment, nor was sorptivity, whilst concrete electrical resistivity increased after the treatment, indicating a mild "sealing" effect on the surface.

The concrete porosity, which was measured on small fragments, was substantially decreased when a current of $0.5 \mathrm{~A} \mathrm{~m}^{-2}$ was applied, whilst it even increased when a current of $2 \mathrm{~A} \mathrm{~m}^{-2}$ was applied. This was attributed to possible opposing side effects of the applied current.

Since the presence of a carbonated layer of concrete is very likely in reinforced concrete structures, the application of electroosmotic injection treatments in real conditions should always be carefully evaluated, in particular with respect to the effectiveness of the involved transport phenomena.

\section{ACKNOWLEDGEMENTS}

The authors acknowledge the European Research Council for supporting the exchange program DOSECOPS (Project No. FP7-PEOPLE-2011-IRSES-294555) and the Guangdong Province Key Laboratory of Durability for Marine Civil Engineering of Shenzhen University for hosting Dr. Torabian Isfahani and performing MIP tests. 


\section{REFERENCES}

[1] I. Llorente, S. Fajardo, J. M. Bastidas, J. Solid. State Electrochem. 2014, 18, 293.

[2] M. Castellote, S. Botija, J. Appl. Electrochem. 2011, 41, 695.

[3] J. Kubo, S. Sawada, C. L. Page, M. M. Page, Mater. Corros. 2008, 59.

[4] E. Redaelli, L. Bertolini, J. Appl. Electrochem. 2011, 41, 817.

[5] L. Bertolini, B. Elsener, P. Pedeferri, E. Redaelli, R. Polder, Corrosion of Steel in Concrete. Prevention, Diagnosis, Repair, Wiley-VCH, Weinheim 2013.

[6] H. E. Cardenas, Nanomaterials in Concrete: Advances in Protection, Repair, and Upgrade, Destech Publications, Lancaster 2012.

[7] M. Sánchez, M. C. Alonso, R. González, Constr. Build. Mater. 2014, 66, 306.

[8] H. Wu, F. Torabian Isfahani, W. Jin, C. Xu, E. Redaelli, L. Bertolini, Constr. Build. Mater 2016, 126, 857.

[9] G. Fajardo, A. Cruz-López, D. Cruz-Moreno, P. Valdez, G. Torres, R. Zanella, Constr. Build. Mater. 2015, 76, 158.

[10] H. Du, S. Du, X. Liu, Constr. Build. Mater. 2014, 73, 705.
[11] F. Torabian Isfahani, E. Redaelli, F. Lollini, W. Li, L. Bertolini, Adv. Mater. Sci. Eng 2016, 2016, 1.

[12] R. J. Hunter, Zeta Potential in Colloid Science. Principles and Applications, Academic Press, New York 1981.

[13] M. Castellote, I. Llorente, C. Andrade, Cement Concrete Res. 2006, 36.

[14] L. Bertolini, L. Coppola, M. Gastaldi, E. Redaelli, Constr. Build. Mater. 2009, 23, 254.

[15] Y. Elakneswaran, T. Nawa, K. Kurumisawa, Cement Concrete Comp. 2009, 31, 72.

How to cite this article: Redaelli E, Torabian Isfahani F, Lollini F, Wu HT, Bertolini L. Effect of electroosmotic flow of aqueous suspension of nanosilica on the properties of carbonated concrete. Materials and Corrosion. 2018;69:89-97. https://doi.org/10.1002/maco.201709528 